\title{
Pre-inoculation of clover seed for aerial seed- ing on logged sites
}

\author{
B.M. BROOKE, D.G. STOUT, R. TUCKER, AND C.M. PRESTON
}

Authors are forage technician and scientist, Agriculture Canada, Research Station, Kamloops, B.C., Canada V2B 8A9; regional planning agralogist, B.C. Ministry of Forests, Kamloops, B. C., Canada V2C 2T7; and research scientist, Forestry Canada, Pacific Northwest Centre, Victoria, B.C., Canada V8Z 1 M5.

\begin{abstract}
In 1989 a mixture of clover (Trifolium hybridum $\mathrm{L}$. and $T$. repens $L$.) seed pre-inoculated with Rhizobia by 2 commercial techniques (Guardcoat ${ }^{\mathrm{TM}(1)}$ and Dormal ${ }^{\mathrm{TM}(1)}$ ) were compared to bare seed. The Guardcoat produced nodulation on $30 \%$ of the clover plants. Dormal and bare seed produced no nodules. Fiftynine percent of the $N$ in clover top growth in 1990 was derived from atmospheric nitrogen. Use of a pre-inoculated treatment, such as Guardcoat, is an effective method of delivering Rhizobia to aerially seeded clover.
\end{abstract}

Key Words: logging, coated seed, clover (alsike, white), Nfixation, ${ }^{15} \mathrm{~N}$ natural abundance

Clearcut-logged areas in interior British Columbia are seeded with domestic forage species for forage production, soil improvement, native vegetation control, and erosion control. Because the sites are typically too rough, steep, and log-strewn to allow conventional cultivation, the seed is sown by aircraft. Sites are selected on the basis of the need for the revegetation as well as on the presence of seedbed suitable for broadcast sowing. In normal practice, site scarification is done for tree regeneration and not specifically for establishment of forages; thus less mineral soil is exposed than would be optimum for forage establishment. Mixtures of legume and grass species adapted to site conditions are sown at a low density $(3 \mathrm{~kg} / \mathrm{ha})$ to minimize potential competition with conifer regeneration.

Soils on these sites may lack the appropriate Rhizobium nodule bacteria, and are nitrogen-poor (Hendrickson and Burgess 1989), so legume seed inoculation may be beneficial. Standard field inoculation, with peat-base inoculum and a sticker solution, is not convenient for the current aerial seeding program. Weather conditions are an important consideration in timing of the seeding, particularly for aeroplanes based far from the clearcuts. If a seed lot has been inoculated and loaded on the aircraft, and weather deteriorates, the load must be removed and then re-inoculated when conditions improve.

Pre-inoculation treatments are available to replace field inoculation. Typical pre-inoculation products are designed to provide a more favorable microenvironment for the bacteria, to ensure its safe delivery to the soil, and thereby to facilitate nodulation. In this study, 2 commercially available pre-inoculation products were evaluated on clover. The natural-abundance method of $\mathrm{N}$ isotope dilution was used to determine the proportion of $\mathrm{N}$ derived from the atmosphere by $\mathrm{N}$-fixation.

We gratefully acknowledge the technical assistance of G. Majak, M. Marginet, K. McCullough, and G. Baalim, and the financial support provided by Grow Tec, Ltd. Edmonton, Alberta. We would like to thank Dr. John Hall for statistical advice and for reviewing the manuscript. Dr. A. van Ryswyk provided the soil description.

Manuscript accepted 18 Feb. 1992.

IUse of a trademark does not guarantee the product by Agriculture Canada and does not imply its approval to the exclusion of other suitable products.

\section{Materials and Methods}

\section{Study Area}

The study was done in a 20 -ha clearcut at $1,430-\mathrm{m}$ elevation northwest of Kamloops near McGillivray Lake. The site lies within the biogeoclimatic zone (Lloyd et al. 1990) described as Thompson Dry Cold Engelmann Spruce-Subalpine Fir Variant with mesic to submesic soil moisture regime. Soil is classified (Agriculture Canada Expert Committee on Soil Survey 1987) as Podzolic Gray Luvisol (Boralf, U.S.A. equivalent) with medium fine to fine texture on morainal materials. Engelmann spruce (Picea engelmannii Parry) had been harvested from the area in 1988. The research site was on a gently rolling, SSE-facing slope. It had been dragscarified during the fall of 1988 .

\section{Seed Pre-inoculation Treatments}

In 1989, 2 commerical pre-inoculation products were tested on a clover seed mix of $67 \%$ alsike (Trifolium hybridum L.) and $33 \%$ white ( $T$. repens $L$.). The Dormal pre-inoculant was a clay-base product from Urbana Laboratories/Research Seeds, St. Joseph, Mo. It added no significant weight to the seed, the material apparently being held electrostatically. The Guardcoat pre-inoculant was a multi-layer lime coat from Grow Tec, Ltd., Edmonton, Alta. This product added weight to the seed, so that $33 \%(w / w)$ of the coated product was coating material. Both treatments were applied to each clover species separately in the Grow Tec laboratory, with the same inoculum for each clover species. The coated clover seeds were then mixed with uncoated orchardgrass (Dactylis glomerata L.) seed at a ratio, by seed numbers, of $40 \%$ orchardgrass, $40 \%$ alsike, and $20 \%$ white clover. The mixed seed was double-bagged in woven polypropylene (@ $25 \mathrm{~kg}$ ), transported by bus to Kamloops, and stored in an unheated warehouse for 5-days before seeding.

\section{Seeding}

Three parallel 500-m lines, extending up the slope, and with centers 120-m apart were established. Each line received a different seeding treatment. A $1-\mathrm{m}$ wide observation strip was delineated with twine down the center of the south $100 \mathrm{~m}$ of each line. Worker traffic was excluded from this area, to protect the soil from disturbance that might influence plant establishment. On 30 May 1989, seed was applied at 3-kg/ ha with a gas driven 'Isolair' bucket seeder slung under a helicopter. Three passes were made on each line, to give a $30-\mathrm{m}$ wide seeded strip. The order of line location and seeding was bare, Guardcoat, Dormal.

\section{Measurements}

To determine actual seeding rate, 20 traps, $0.09-\mathrm{m}^{2}$ milk crates lined with plastic bags, were placed at 5 -m intervals on alternate sides of the observation strip.

To determine establishment, 20 permanent $0.25-\mathrm{m}^{2}$ plots were established $5 \mathrm{~m}$ apart within the observation strip. The corners of plots were marked with spikes and nylon twine was strung around them. Plants were counted on 4 dates: 8, 20, and 29 June, and 12 September. During the first count, a visual estimate of the percen- 
tage of suitable seedbed in each plot was recorded. Seedbed judged to be suitable for forage species establishment included bare mineral or organic soil and mineral soil mixed with a moderate amount of litter; seedbed not suitable for forage production was that covered with twigs, logs, rocks, and duff.

The actual species composition of each seed mix and the species viability were measured for representative samples from each mix by the Agriculture Canada Research Station in Saskatoon. Duplicate samples, with no clover species separation, were tested for germination at the Kamloops Station (four 100-seed replicates/ treatment, 7 days at $20^{\circ} \mathrm{C}$ ). Viability results from Saskatoon were weighted for species composition to allow inclusion with the Kamloops results on mixed seed. Hard seeds were not considered germinable.

To determine the viability of the inoculum on the seeds as sown, samples collected from the seed traps and stored 2 months at $6^{\circ} \mathrm{C}$ were analyzed for MPN (most probable number of live bacteria) by Norwest Labs, Nisku, Alberta.

Nodulation on clover plants was evaluated on 19 July and 14 August. On each occasion, a random sample of 40 plants was dug from a new $100-\mathrm{m}$ transect parallel to the observation strip and 5-m from its center. Sampling points were at 5-m intervals along the transect with the 2 plants closest to each point being evaluated. Nodules were rated for number, size, color, position on root, and a weighted score was calculated (Rice et al. 1977).

On 10 September, 1990 clover plants were dug from the Guardcoat treatment and divided into 2 groups: nodulated ( $\mathrm{N}$-fixing) and non-nodulated (non-fixing). The growth above ground level was then removed. At this time the plants had set seed, and the leaves were largely bleached and subject to shattering. Many of the nodules had white or green interiors, occasionally withered at lobe tips, or completely wizened. Collection of samples for measurement of $\mathrm{N}$-fixation was done on a transect running from the $100-\mathrm{m}$ to the $500-\mathrm{m}$ point on the seeded line, with each $100-\mathrm{m}$ portion being considered as a plot. Within each plot 2 plants, for each of the fixing and non-fixing categories, were taken at $20-\mathrm{m}$ intervals. To provide sufficient tissue for laboratory analysis, relatively large plants were used. The 10 plants collected per plot were dried at $60^{\circ}$ $\mathrm{C}$ in a forced-air oven, bulked, then ground to pass 1-mm mesh, for 2- to 17-g of material. A 250-mg sample was analyzed for total Kjeldahl N (modified to include nitrate), the distillates converted to $\mathrm{N}_{2}$ gas using lithium hypobromite, and the $\mathrm{N}_{2}$ gas analyzed for atom percent ${ }^{15} \mathrm{~N}$ using a VG Isogas SIRA 9 Mass Spectrometer, as described previously (Preston et al. 1990). To ensure accuracy, each sample was split into 2 subsamples after acidification for the ${ }^{15} \mathrm{~N}$ analysis, and 1 sample from each treatment was replicated for the complete total $\mathrm{N}$ and ${ }^{15} \mathrm{~N}$ analysis.

The percentage of $\mathrm{N}$ derived from the atmosphere (\% Ndfa), was calculated using the difference between fixing and non-fixing systems, according to Ledgard et al. (1985):

$\% \mathrm{Ndfa}=100 \times\left[\left(\right.\right.$ atom $\%{ }^{15} \mathrm{~N}\{\mathrm{nfs}\}-$ atom $\left.\%{ }^{15} \mathrm{~N}\{\mathrm{fs}\}\right) /\left(\right.$ atom $\left.\left.\%{ }^{15} \mathrm{~N}\{\mathrm{nfs}\}-\mathrm{B}\right)\right]$,

where nfs refers to a non-fixing system, fs refers to an $\mathrm{N}$-fixing system, and B is the atom $\%{ }^{15} \mathrm{~N}$ for a legume grown solely on atmospheric $\mathrm{N}$. It was assumed that $\mathrm{B}=0.36652$ as reported for subterranean clover (Ledgard et al. 1985).

\section{Statistical Analysis}

Plots were the experimental units for percent seed bed, number seeds sown $/ \mathrm{m}^{2}$, and percent seedling establishment. For nodulation, the units were individual plants, and for percent germination they were seed samples analyzed by each laboratory. For plant establishment a log transformation was done to stabilize the standard deviation before doing analysis of variance. The backtransformed means are presented. The seed test variables were in a randomized complete block design with laboratories as blocks. In

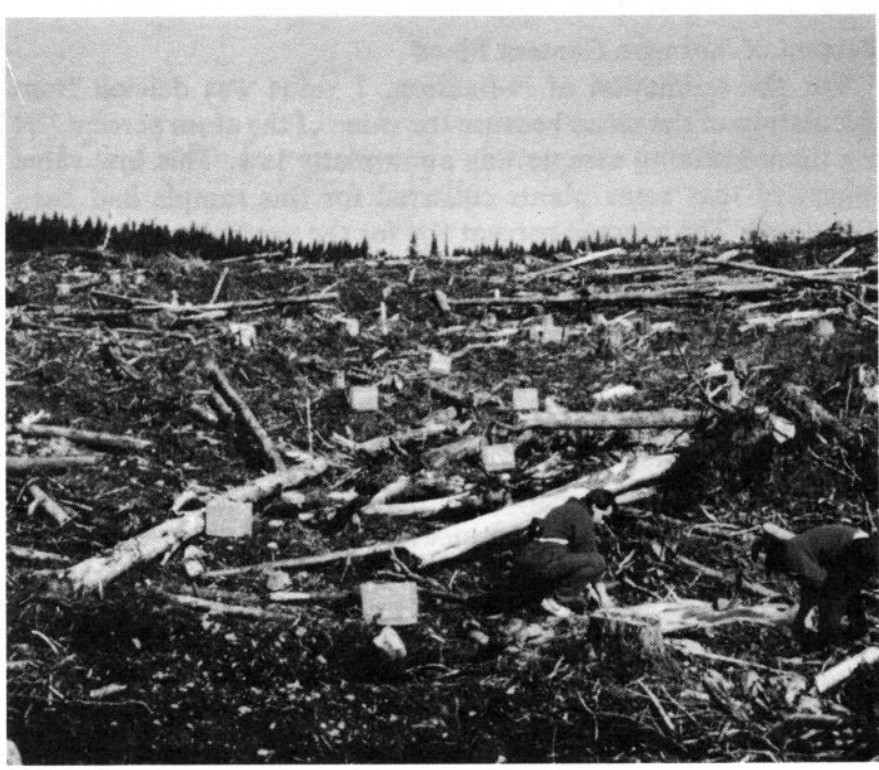

Fig. 1. Researchers with the seed traps used to measure the seeding rate delivered by the helicopter.

the analysis of variance of percent seed bed, number seeds sown $/ \mathrm{m}^{2}$ and seed viability, the variance was partitioned into pre-inoculation treatment effect and error. For seedling establishment the variance was partitioned into pre-inoculation treatment, date, treatment by date, and error effects. Significance was tested at $P<0.05$, but the results of the analyses must be interpreted with caution as the error was based on subsampling rather than on true replication.

\section{Results}

\section{Clover Establishment}

Seeding by helicopter resulted in no significant difference between treatments in clover seed distribution, with an average of 321 seeds $/ \mathrm{m}^{2}(\mathrm{SE}=18, \mathrm{n}=60)$. The plot areas estimated to be suitable for seedling establishment were not significantly different for treatments and averaged $34 \%(\mathrm{SE}=4, \mathrm{n}=60)$. The intended species ratio in the mixes was 2 alsike : 1 white, but actual ratios were $2: 1,3: 1$, and $3: 1$ for the bare, Dormal and Guardcoat treatments, respectively. Alsike clover had $87 \%$ germination compared to $73 \%$ for the white clover. Pre-inoculation treatments did not significantly affect either germination of the mixed seed $(86 \%, \mathrm{SE}=$ $2, \mathrm{n}=6)$ or hard seed content $(2.5 \%, \mathrm{SE}=0.2, \mathrm{n}=6)$.

Clover establishment increased from 8 June to 29 June (4.9 to 21.2 seedlings $/ \mathrm{m}^{2}$ ), followed by some mortality during the summer, as reflected in the final count on 12 September $\left(12.8\right.$ seedlings $\left./ \mathrm{m}^{2}\right)$. The pre-inoculation treatment by date interaction was not significant. Neither Guardcoat nor Dormal significantly increased average establishment of sown seed compared to the bare seed control. By the end of the first growing season, $4 \%$ (14\% from actual data rather than from backtransformed data) of sown seeds had established.

\section{Root Nodulation}

In 1989, nodulation was observed on the Guardcoat treatment: $38 \pm 8 \%$ (mean \pm SD) on 19 July and $22 \pm 6 \%$ on 14 August. No nodules were observed on the other 2 treatments. When tested 2 months after seeding, neither the Dormal pre-inoculated seeds nor the bare control seeds contained viable bacteria: $M P N=2.1$ and MPN $=6.5$, respectively. The MPN for the Guardcoat treated seed was 15,100 . On plants from the Guardcoat treatment, nodule quality was rated at 4.5 out of 10 on 19 July and 6.8 out of 10 on 14 
August. Plants as small as the first trifoliate stage were nodulated.

\section{Percent of Nitrogen Content Fixed}

For the estimation of $\mathrm{N}$-fixation, 1 value was deleted from calculation of the mean because the value of the atom percent ${ }^{15} \mathrm{~N}$ for the non-fixing sample was abnormally low. This low value suggested that some plants collected for this sample had been nodulated. The average percent ${ }^{15} \mathrm{~N}$ for the nonfixing system was $0.36953 \pm 0.00060$ (mean $\pm S D, n=3$ ) and for the fixing system was $0.36767 \pm 0.00014(n=4)$. Estimates of $N_{2}$ fixation showed that nodulated clover plants obtained $58.7 \pm 9.7 \%$ (mean $\pm \mathrm{SD}, \mathrm{n}$ $=3$ ) of their top growth $\mathbf{N}$ content from the atmosphere.

\section{Discussion}

According to the regulations of the Fertilizers Act (Agriculture Canada 1990), a sample of pre-inoculated seed is rated satisfactory if the upper $95 \%$ confidence limit for the MPN/seed is $10^{3}$. However, official test results for Dormal, obtained after this trial was begun, showed values below $10^{3}$ for 1987-1989 (performance records, pre-inoculated clover seed, Feed and Fertilizer Division, Agriculture Canada). As a result of these official tests, the company producing Dormal agreed to take pre-inoculated clover seed inoculum off the market in 1990 (pers. commun., M. Kenney). To determine the likelihood that the Dormal product we had used had a low Rhizobia number, MPN counts were done on seeds stored 2 months at $6^{\circ} \mathrm{C}$. Dormal seed tested at this time had no viable Rhizobia, so it is concluded that they bore no viable inoculum at the time of seeding. The upper limit measured for Guardcoat following 2 months' storage, $42,000 \mathrm{MPN} /$ seed, exceeded the required minimum.

The complete failure of the Dormal product was unexpected. On operational seedings in previous years, nodulation had been observed on similar sites seeded with Dormal pre-inoculated clover (unpublished data, R. Tucker). Although this study provides a valid test of the Dormal product produced in 1989, it does not provide a valid comparison of the 2 different methods of preinoculation used in the study. The Dormal treatment was the equivalent of an uninoculated bare seed treatment and the data from it are useful because they provide further evidence that native Rhizobia do not exist on this clearcut. The designated bare treatment and the Dormal treatment were located on either side of the Guardcoat treatment. The nodulation by Guardcoat compared to the other 2 treatments was sufficiently dramatic that it is unlikely to be a statistical artifact; owing to this fact and the uncertainty that a viable Dormal product could be obtained, this trial was not replicated in time.

The ${ }^{15} \mathrm{~N}$ natural-abundance method of estimating $\mathrm{N}$-fixation was shown to be useful on a clearcut site. Nodulated clover plants obtained $59 \%$ of their top growth $\mathrm{N}$ content from the atmosphere. For comparison, isotope measurements in a field study in California with 'Ladino' white clover and 'Wimmera' ryegrass (Lolium rigidium $\mathrm{L}$.) indicated that the clover obtained 85 to $100 \%$ of its $\mathrm{N}$ from the atmosphere (Broadbent et al. 1982). Ryegrass, when grown in a mixture with the white clover, obtained $79 \%$ of its nitrogen through transfer from the clover once the stand was established for 6 months. For this reason, nitrogen-fixing clover is expected to benefit grass and tree growth on this clearcut. In addition, any soil $\mathrm{N}$ not used by the clover is available for the use by the other species on the site (Phillips et al. 1986).

Because nodulated clover plants obtained a significant amount of nitrogen from the atmosphere, and because seed inoculation increased the number of plants nodulated, it is concluded that inoculating seed for this type of site is beneficial. This trial was designed to simulate operational conditions as closely as possible with available resources. To fully evaluate performance of Guardcoat pre-inoculation under operational conditions other aspects, such as storage life of preinoculated seed and use of aeroplanes, warrant further research.

\section{Literature Cited}

Agriculture Canada Expert Committee on Soll Survey. 1987. The Canadian system of soil classification. $2^{\text {nd }}$ ed. Agr. Can. Pub. 1646. Ottawa.

Agriculture Canada. 1990. The method of testing legume inoculant and preinoculated seed products. Fertilizers Act, Section 23, Regulations. Canada Dep. Agr., Ottawa, Ontario.

Broadbent, F.E., T. Nakashima, and G.Y. Chang. 1982. Estimation of nitrogen fixation by isotope dilution in field and greenhouse experiments. Agron. J. 74:625-628.

Hendrickson, 0.Q., and D. Burgess. 1989. Nitrogen-fixing plants in a cutover lodgepole pine stand of southern British Columbia. Can. J. Forest. Res. 19:936-939.

Ledgard, S.F., J.R. Simpson, J.R. Freney, and J. Bergersen. 1985. Effect of reference plant on estimation of nitrogen fixation by subterranean clover using ${ }^{15 N}$ methods. Aust. J. Agr. Res. 36:663-676.

Lloyd, D., K. Angove, G. Hope, and C. Thompson. 1990. A guide to site identification and interpretation for the Kamloops Forest Region. British Columbia Ministry of Forests Land Management Handbook 23. Research Branch, B.C. Ministry Forests, Victoria.

Phillips, D.A., M.B. Jones, and K.W. Foster. 1986. Advantages of the nitrogen-15 dilution technique for field measurements of symbiotic dinitrogen fixation in legumes. p. 11-16. In: R.D. Hauk and R.W. Weaver (ed). Field measurement of dinitrogen fixation and denitrification. SSSA Special Pub. 18, SSSA Inc., Madison, Wisc.

Preston, C.M., V.G. Marshall, and K. McCullough. 1990. Fate of $15 \mathrm{~N}-$ labelled fertilizer applied on snow at two forest sites in British Columbia. Can. J. Forest. Res. 20:1583-1592.

Rice, W.A., D.C. Penny, and M. Nyborg. 1977. Effects of soil acidity on Rhizobium numbers, nodulation and nitrogen fixation by alfalfa and red clover. Can. J. Soil Sci. 57:197-203. 